\title{
(4)
}

\section{Um estudo sobre o ensino do shodô a partir de manuscritos*}

Rodrigo Moura Lima de Aragão

\section{Resumo}

Propôs-se apreender aspectos do ensino da arte da caligrafia japonesa (shodô), a partir da análise de um conjunto de manuscritos feitos por um aprendiz nas aulas de shodô da Esperança Fujinkai (São Paulo), entre fevereiro de 2004 e julho de 2005. Estabeleceram-se, para a análise, dois escopos: conteúdo e seu desenvolvimento; aspectos observados na correção. A partir do primeiro, observaram-se quais grafias e estilos foram desenvolvidos ao longo das aulas de shodô, assim como de que forma se deu esse desenvolvimento, isto é, quando foram apresentados novos estilos e caracteres, com que ritmo isso ocorreu, em que formato foi feito o trabalho nos manuscritos, etc. Já por meio do segundo escopo, verificou-se que as correções e observações da professora de shodô voltaram-se a aspectos de três níveis da produção do aluno: traço; caractere; caractere e sua relação com o conjunto.

Palavras-chave: ensino do shodô; caligrafia japonesa; ensino de arte.

* Agradeço, em especial, à professora Madalena Hashimoto Cordaro, pela leitura atenta que fez deste trabalho e pelas preciosas sugestões que deu para sua composição, e, ainda, à professora Shoka Kodera, pelo esmero que tem tido no ensino da bela arte da caligrafia japonesa.

\section{Abstract \\ A study on the teaching of shodo from manuscripts}

One proposed to apprehend aspects of the teaching of the Japanese calligraphy (shodo), from the analysis of a set of manuscripts made by an 
apprentice in the classes of shodo of the Esperança Fujinkai (São Paulo), between February, 2004 and July, 2005. For the analysis, two approaches were established: content and its development; aspects observed in the correction. From the first approach, one observed which graphics and styles were developed during the lessons of shodo, as well as how this development happened, i.e., when new styles and characters were presented, how often this occurred, in which format the work in the manuscripts was made, etc. From the second, one verified that the corrections and comments of the shodo teacher concerned the aspects of three levels of student production: trace; character; character and its relation to the set.

Keywords: shodo teaching; Japanese calligraphy; art teaching.

\section{Introdução}

O ensino da caligrafia japonesa no município de São Paulo se dá em escolas tradicionais japonesas (nihonjingakkô) e em espaços outros, como associações desportivas e culturais, associações de província (kenjikai), associações de senhoras (fujinkai) e de anciãos (rôjinkai). No primeiro caso transmite-se o shûji, exercício no qual se busca compor apenas uma caligrafia correta e bem escrita, "recebendo ênfase os caracteres legíveis e caprichados" (Sato, 1999, p. 9). ${ }^{1}$ Já nos demais ensina-se o shodô, arte da caligrafia japonesa na qual os praticantes visam tanto aquilo que se pretende no shûji quanto a constituição de, como coloca Sato (1999), linhas vivas, com força e energia. Este trabalho volta-se ao ensino desta última.

Shodô é, fundamentalmente, uma arte de linhas (Mikami, Tanahashi, 1961) e possui dois elementos formais: a linha preta e o espaço branco (Sato, 1999). A linha resulta do contato do pincel fude, umedecido pela tinta sumi, com o papel washi; o espaço é o próprio papel, chinês, japonês ou coreano (Sato, 1999). A apreensão dessa arte efetiva-se, pois, conforme o praticante adquire domínio desses dois elementos, ou seja, à medida que se torna proficiente, por exemplo, na confecção de linhas retilíneas, curvas, pontiagudas e arredondadas, e explora o espaço branco com equilíbrio.

A atuação do professor (ou sensei) de shodô no aprendizado dos alunos dirige-se, então, sobretudo, a uma execução bem-sucedida dos traços de que se constituem os inúmeros caracteres chineses e japoneses e a um uso adequado do espaço. Dá ele, geralmente, orientações aos alunos antes do início da prática artística, apresentando-lhes particularidades dos caracteres a serem executados e aspectos do conjunto que por estes é formado, e norteia os aprendizes ainda ao longo e no término dessa prática.

Nos esclarecimentos que profere antes do exercício do shodô, o sensei emprega como ferramentas, comumente, modelos impressos e aqueles que ele próprio fez, chamados de tehon, nos quais se encontram os caracteres

\footnotetext{
"In the Japanese practice of shuji, or handwriting, the emphasis is on neat, legible characters" (Sato, 1999, p. 9).
} 
escolhidos para uma aula específica ou uma seqüência de aulas. Já na orientação que se dá durante e após a elaboração dos manuscritos o professor utiliza, freqüentemente, um pincel fude e uma tinta laranja, shuboku, com os quais, em geral, remenda os traços dos alunos, apresenta formas corretas na realização das linhas e circula os componentes bem executados.

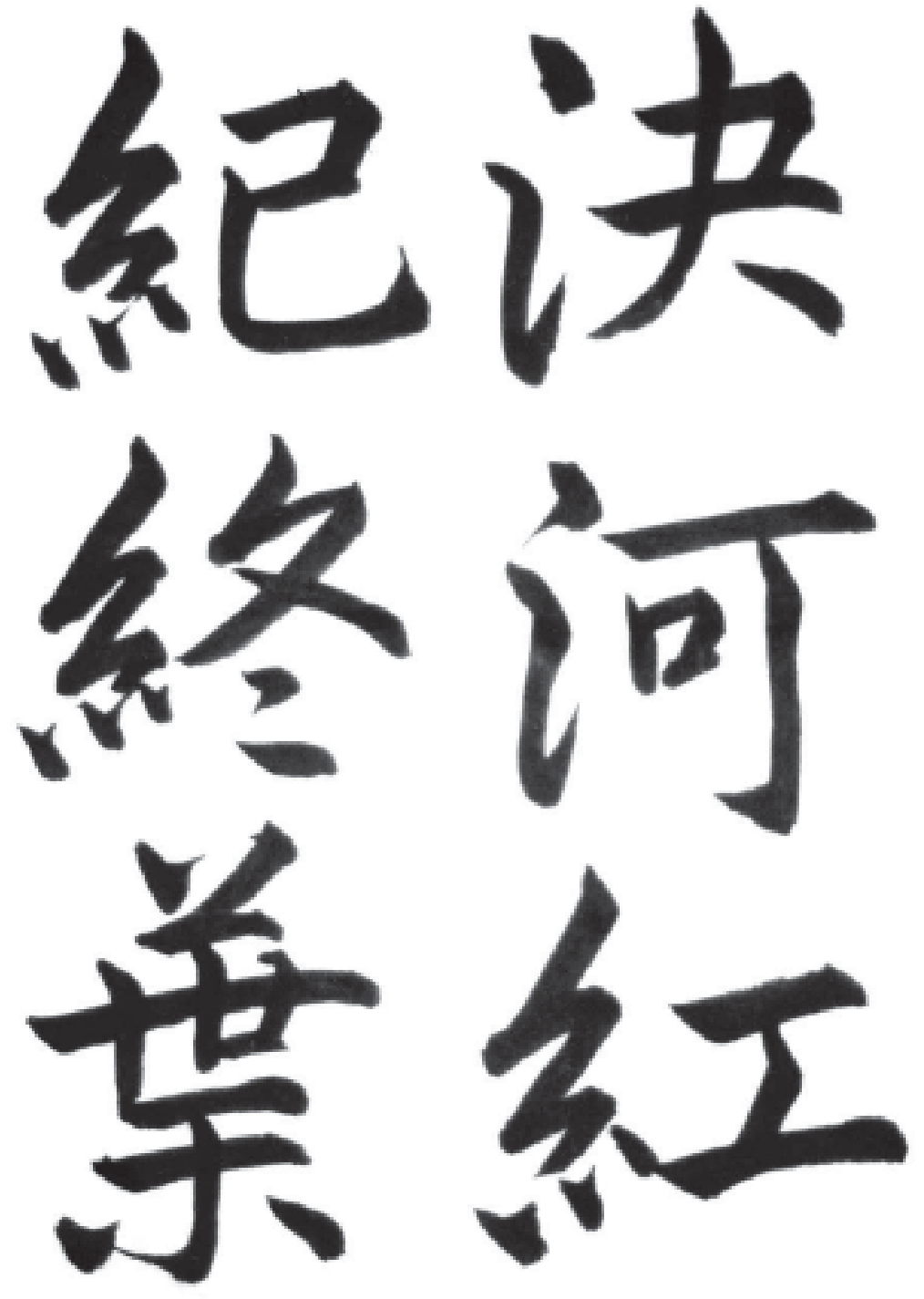

Figura 1 - Modelo de caligrafia (tehon), de Shoka Kodera (cortesia da professora) de shodô 


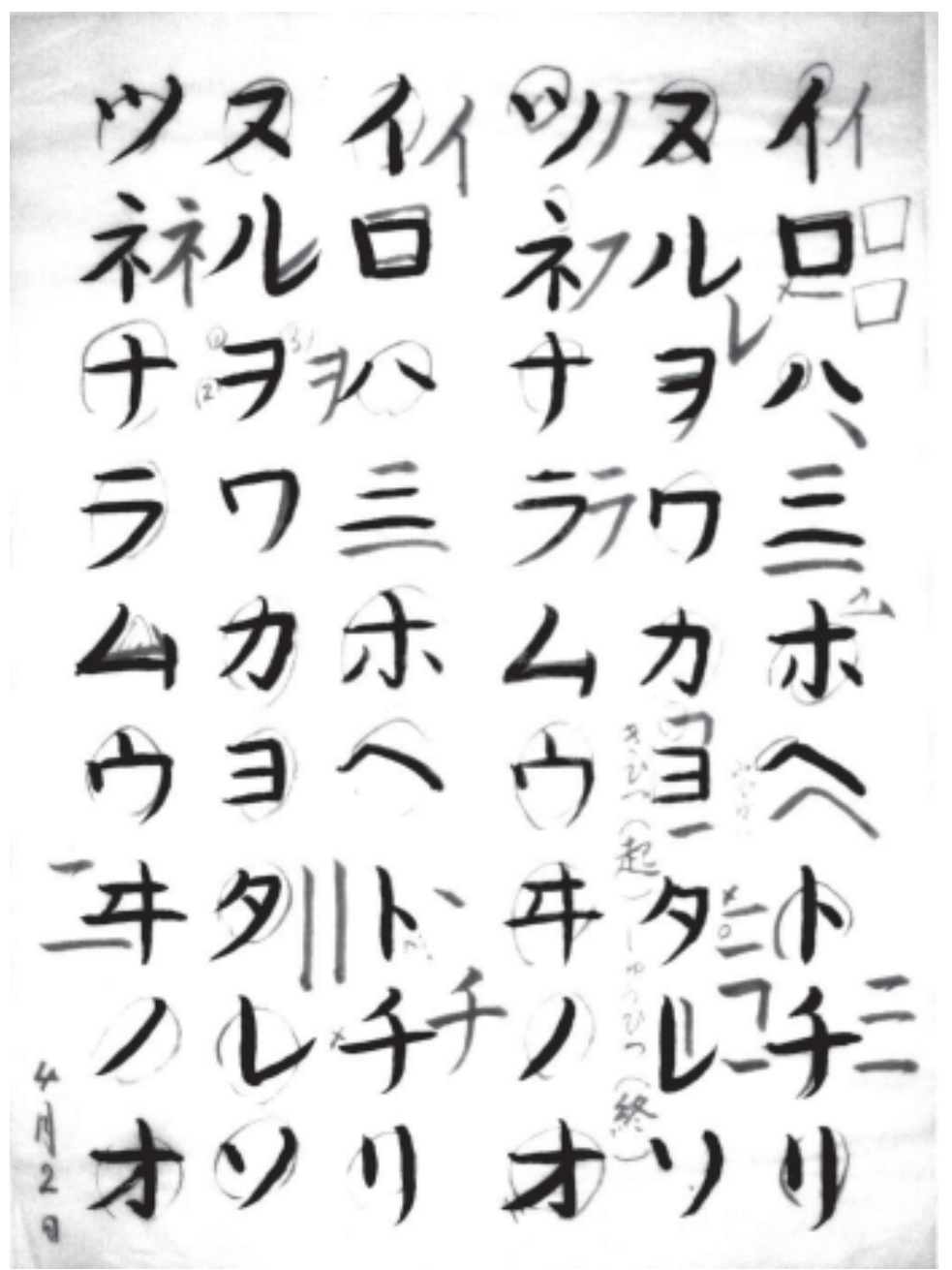

Figura 2 - Manuscrito com correções e observações do professor (acervo do autor)

No decorrer das aulas, assim, é possível aos alunos constituir acervos de manuscritos, nos quais constarão: escolhas feitas pelo professor quanto ao conteúdo (os caracteres praticados, por exemplo); estratégias empregadas pelo sensei para o desenvolvimento desse conteúdo (como quantos caracteres foram feitos por manuscrito e sua variedade); erros, acertos e inúmeras correções e observações feitas pelo professor quanto ao trabalho do aprendiz.

Assumindo-se, então, que metodologia do ensino de arte refere-se às orientações educativas cujo objetivo é contribuir para a apreensão de noÇões e habilidades em arte por parte dos alunos (Ferraz, Fusari, 1991), ${ }^{2}$ entende-se que, nesses manuscritos, há o registro de parte desses encaminhamentos educativos, particularmente de uma porção daqueles próprios à arte da caligrafia japonesa. Caso se pretenda estudar o ensino do shodô, então, a análise desses manuscritos é um trajeto a ser considerado, pelos retratos que pode fornecer desse processo ensino-aprendizagem.

\footnotetext{
2 Embora o trabalho das autoras trate, principalmente, do ensino de arte no ambiente escolar, o conceito de metodologia do ensino de arte apresentado por elas, em especial, cabe aos cursos de arte como um todo, não sendo inapropriada, pois, sua transposição ao ensino da arte da caligrafia japonesa, que se dá fora das escolas.
} 
No projeto do qual este trabalho faz parte, ${ }^{3}$ tenciona-se compor um panorama das metodologias empregadas no ensino do shodô no município de São Paulo. Neste estudo, espera-se apreender fragmentos desse todo, especialmente por meio da análise de um conjunto de manuscritos ${ }^{4}$ elaborados ao longo das aulas de shodô da Esperança Fujinkai ${ }^{5}$ (bairro da Liberdade, São Paulo), entre fevereiro de 2004 e julho de 2005. Trata-se de um primeiro esforço voltado para o registro e compreensão de como se processa o ensino da arte da caligrafia japonesa, em São Paulo, e afasta-se dos estudos feitos até o momento acerca do shodô nesse município - a única pesquisa realizada (e publicada) foi a de Saito (2004), situada sob o campo da Semiótica.

\section{Materiais e métodos}

A análise efetuada neste trabalho abrangeu um total de 171 manuscritos produzidos nas aulas de shodô da Esperança Fujinkai, entre fevereiro de 2004 e julho de 2005. Investigou-se, em particular, a produção de um aluno sem ascendência japonesa, a qual - pressupôs-se - apresenta aspectos de como esse aprendiz foi conduzido, pela professora dessa associação, ao longo de seu desenvolvimento inicial na arte da caligrafia japonesa. Assemelha-se o percurso deste estudo, pois, àquilo que Ginzburg (1990) chamou de "paradigma indiciário": partiu-se de indícios mínimos, os quais, acreditase, possibilitaram compreender fenômenos mais gerais de uma realidade opaca - e "opaca", aqui, se deve ao fato de que não havia registros no que

${ }^{3}$ O nome do referido projeto é $\mathrm{Pa}-$ norama das metodologias de ensino da arte da caligrafia japonesa, shodô, no município de São Paulo. Trata-se de uma pesquisa de iniciação científica, que vem sendo realizada no Centro de Estudos Japoneses da Universidade de São Paulo, sob orientação da professora Dra. Madalena Hashimoto Cordaro e com financiamento do governo da província de Toyama, Japão. ${ }^{4}$ A produção analisada neste estudo é resultado do trabalho do autor nas aulas de shodô da Esperança Fujinkai. Para a exposição da pesquisa neste artigo, entretanto, optou-se por não fazer referência aos manuscritos ou ao aprendiz em primeira pessoa e escolheu-se, ainda, referir-se à professora de shodô como "professora" ou "sensei", e não pelo seu nome (a não ser nos modelos de sua autoria). Ambas as escolhas visaram evitar uma aproximação com os objetos de estudo, a qual, acredita-se, seria prejudicial ao trabalho.

${ }^{5}$ A Esperança Fujinkai (ou Associação Beneficente Feminina Esperança) é uma associação de senhoras que promove cursos e atividades artísticas e culturais diversas e localiza-se no prédio da Sociedade Brasileira de Cultura Japonesa (Bunkyo), na Liberdade, em São Paulo. diz respeito ao ensino do shodô em São Paulo.

A realização dessa análise exigiu, primeiramente, o estabelecimento de dois pontos fundamentais: escopo; método.

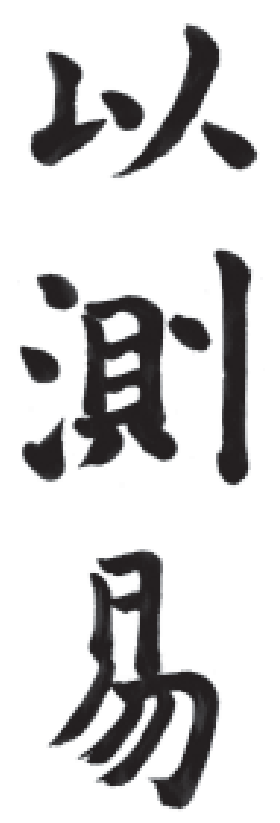

Figura 3 - Exemplos de kanji (caligrafia do autor) 
Para se definir o que seria visado no exame da produção artística, partiu-se do contraste entre aquilo que envolve metodologia do ensino de arte e os próprios manuscritos. Opôs-se, especificamente, o que havia nessa produção à idéia de que metodologia do ensino, no caso da arte, inclui escolhas do professor quanto aos tópicos em arte e refere-se às trajetórias pedagógicas dirigidas à elaboração, apreciação e análise de arte (Ferraz, Fusari, 1991) e estabeleceram-se, a partir daí, dois escopos para a investigação: conteúdo e seu desenvolvimento; aspectos observados na correção.

"Conteúdo e seu desenvolvimento" diz respeito tanto aos caracteres e estilos desenvolvidos no decorrer das aulas de shodô quanto à maneira como esse conteúdo foi trabalhado.

Procurou-se identificar quais das grafias utilizadas na língua japonesa foram praticadas no curso da Esperança Fujinkai, entre as seguintes, detalhadas por Suzuki (1985):

Kanji: grafia ideográfica de origem chinesa, usada para grafar termos conceituais.

Katakana: grafia silábica desenvolvida a partir de secção parcial do kanji, empregada contemporaneamente em nomes estrangeiros.

Hiragana: grafia silábica originada a partir de uma escrita cursiva do kanji (sôshotai), utilizada essencialmente para os termos gramaticais da língua japonesa.

\begin{tabular}{|c|c|c|c|c|c|c|c|c|c|}
\hline ラ & ra & 2 & $\mathrm{ma}$ & + & na & $H$ & sa & ア & a \\
\hline 1) & ri & $\vdots$ & $\mathrm{mi}$ & $=$ & ni & $\therefore$ & shi & 1 & i \\
\hline ル & ru & 4 & $\mathrm{mu}$ & 又 & nu & 久 & su & 门 & $\mathrm{u}$ \\
\hline L & re & $x$ & me & 不 & ne & t & se & I & e \\
\hline$\square$ & ro & E & $\mathrm{mo}$ & 1 & no & Y & so & オ & 0 \\
\hline \multirow[t]{4}{*}{7} & wa & $\uparrow$ & ya & ו & ha & 夕 & ta & 力 & ka \\
\hline & & 平 & (yi) & $t$ & i & 千 & chi & x & ki \\
\hline & & 1 & yu & 7 & fu & ツ & tsu & 7 & $\mathrm{ku}$ \\
\hline & & 7 & ( & & e & テ & te & ケ & ke \\
\hline 7 & wo & $\exists$ & yo & 朳 & ho & r & to & 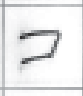 & ko \\
\hline & $\mathrm{n}$ & & & & & & & & \\
\hline
\end{tabular}

Figura 4 - Os quarenta e oito caracteres do katakana e suas respectivas leituras, em papel quadriculado tradicional japonês (escrita do autor) 


\begin{tabular}{|c|c|c|c|c|c|c|c|c|c|}
\hline 3 & ra & £ & ma & $t_{2}$ & na & I & sa & 5 & a \\
\hline (1) & ri & 7) & $\mathrm{mi}$ & $c=$ & ni & $L$ & shi & $v^{\prime}$ & $\mathrm{i}$ \\
\hline 3 & ru & $\omega^{\prime}$ & $\mathrm{mu}$ & $\nless 2$ & nu & $\frac{1}{9}$ & su & 3 & $\mathrm{u}$ \\
\hline K & re & $\not$ & me & 12 & ne & t & se & $\dot{z}$ & e \\
\hline 3 & ro & 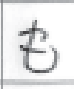 & $\mathrm{mo}$ & (D) & no & $\pi$ & so & $f^{\prime}$ & 0 \\
\hline わ & wa & † & ya & (d & ha & t= & ta & 力 & ka \\
\hline & & 3 & (yi) & 2 & hi & 5 & chi & 丈 & ki \\
\hline & & $(D)$ & yu & 3 & fu & 3 & tsu & $<$ & $\mathrm{ku}$ \\
\hline & & 䒺 & (ve) & & he & Z & te & $1+$ & ke \\
\hline 灰 & Wo & $L$ & yo & ( & ho & z & to & 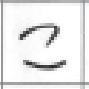 & ko \\
\hline$h$ & $\mathrm{n}$ & & & & & & & & \\
\hline
\end{tabular}

Figura 5 - Os quarenta e oito caracteres do hiragana e suas respectivas leituras, em papel quadriculado tradicional japonês (escrita do autor)

Buscou-se verificar, também, quais estilos foram desenvolvidos nas aulas desse curso, entre os seguintes: ${ }^{6}$

Kaisho: estilo que consiste na escrita padrão ou de fôrma (Nakata, 1983) e que, baseado em poucos movimentos, é rígido e estável (Wakamatsu, 2004). Gyôsho: estilo semicursivo, que não preserva com rigor a forma de cada traço e em cuja prática é empregada uma técnica suave, arredondada (Nakata, 1983) - é um estilo intermediário entre o kaisho e o sôsho (Wakamatsu, 2004).

Sôsho: estilo cursivo que possui flexibilidade em sua forma (Nakata, 1983) e que tem como ponto fundamental o ritmo na escrita (Wakamatsu, 2004).

${ }^{6}$ Nakata (1983) apresenta ainda outros estilos (como o reisho e o tensho, por exemplo). Entretanto, como a produção analisada neste trabalho resulta dos estágios iniciais de aprendizado do shodô, restringiu-se a exposição a esses três estilos principais.

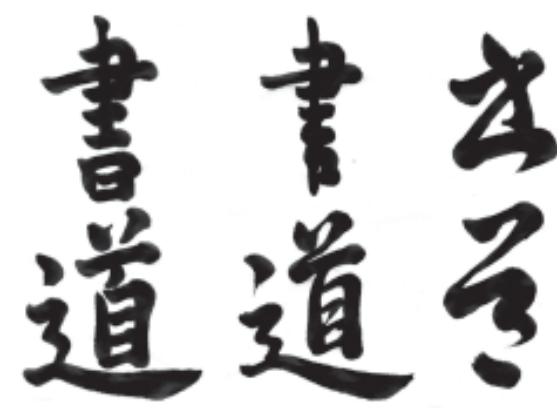

Figura 6 - Ideogramas sho (escrita) e dô (caminho), escritos, da esquerda para a direita, nos estilos kaisho, gyôsho e sôsho (caligrafia do autor) 
Além disso, nesse primeiro escopo, foram observados aspectos relacionados com o desenvolvimento desse conteúdo, quais sejam: quantos caracteres foram feitos por manuscrito; em quais momentos houve maior ou menor variedade de caracteres; quando o aprendiz foi orientado a executar novos caracteres; em que momento se deu início à prática de um novo tipo de grafia ou estilo; outros pontos que porventura se vinculassem à maneira pela qual o conteúdo foi trabalhado no decorrer das aulas.

Já o segundo escopo da análise, "aspectos observados na correção", refere-se àquilo que a professora sinalizou nos manuscritos. Procurou-se verificar, nas correções e observações feitas pela sensei no trabalho do aprendiz, a que elementos da produção de alunos se atém o olhar de um professor de shodô, isto é, a quais características das linhas e do uso do espaço dirige-se sua atenção. À espessura dos traços? À curvatura das linhas?...

Definido o escopo da pesquisa, delineou-se o meio pelo qual os aspectos visados seriam apreendidos, isto é, determinou-se o método de análise.

Observou-se que o estudo de como se deu o trabalho com as grafias ao longo do tempo e de quais momentos foram feitas escolhas X ou Y para o exercício de um estilo, por exemplo, requer uma visão de conjunto, e não de um manuscrito isolado. Notou-se que são visados, em "conteúdo e seu desenvolvimento", padrões perceptíveis, principalmente em seqüências de manuscritos, e não por meio de uma análise isolada.

Por outro lado, verificou-se que a apreensão de aspectos relacionados com a correção dos manuscritos exigiria uma investigação direcionada, sobretudo, ao particular. Cada manuscrito apresenta diferentes observações e correções, e, então, há a necessidade de se examinar cada um deles isoladamente, a fim de se depreender o que foi observado pela professora, de uma forma geral.

A partir dessas considerações, estabeleceu-se como procedimento de análise um percurso de três etapas:

1) análise conjunta de manuscritos;

2) análise isolada de um manuscrito;

3) análise conjunta de manuscritos.

A primeira etapa volta-se ao escopo "conteúdo e seu desenvolvimento"; a segunda, a "aspectos observados na correção"; já a última etapa dirige-se a aspectos que dizem respeito tanto ao conteúdo quanto ao seu desenvolvimento e à correção dos manuscritos. Pretendeu-se, nessa última etapa, captar detalhes do todo que, acredita-se, só poderiam ser vistos após a análise do particular e, ainda, assimilar especificidades das partes que poderiam ser notadas no conjunto de manuscritos, crê-se, apenas depois de uma análise isolada.

Concluído o planejamento da investigação, levou-se a efeito sua execução. Do acervo de manuscritos disponíveis, foram considerados válidos para esta pesquisa somente os produzidos entre fevereiro de 2004 e julho de 2005, com data, o que correspondeu a um total de 171 peças. Esses 
manuscritos foram ordenados cronologicamente e, em seguida, analisados em grupos de 12 manuscritos.

Procedeu-se, pois, da seguinte forma: analisou-se um conjunto de 12 manuscritos, a um só tempo; estudou-se o primeiro desse conjunto de 12 manuscritos, isoladamente; estudaram-se os demais manuscritos, um a um, isoladamente; realizou-se uma segunda análise conjunta dos 12 manuscritos; passou-se para o próximo grupo de 12 manuscritos, e assim se seguiu até que todos os 171 manuscritos fossem analisados.

Os aspectos observados ao longo da análise foram anotados em folhas à parte, a fim de facilitar sua síntese ulterior. No decorrer da investigação, ainda, contrastaram-se os manuscritos com os modelos (tehon) fornecidos pela professora, com o objetivo de extrair, dessa comparação, outros aspectos que pudessem ser relevantes ao foco de análise deste estudo.

\section{Resultados - conteúdo e seu desenvolvimento}

Entre fevereiro de 2004 e julho de 2005, a professora de shodô da Esperança Fujinkai trabalhou com o aprendiz os três tipos de grafia da língua japonesa, isto é, kanji, katakana e hiragana, dois estilos de caligrafia, kaisho e gyôsho, além daquilo que se considerou uma aproximação do sôsho (o hiragana, da forma como foi praticado) e uma aproximação do kaisho (o katakana). ${ }^{7}$ Observou-se, ainda, que foi trabalhado um outro tipo de conteúdo, que não havia sido previsto na etapa de planejamento deste estudo: os traços básicos.

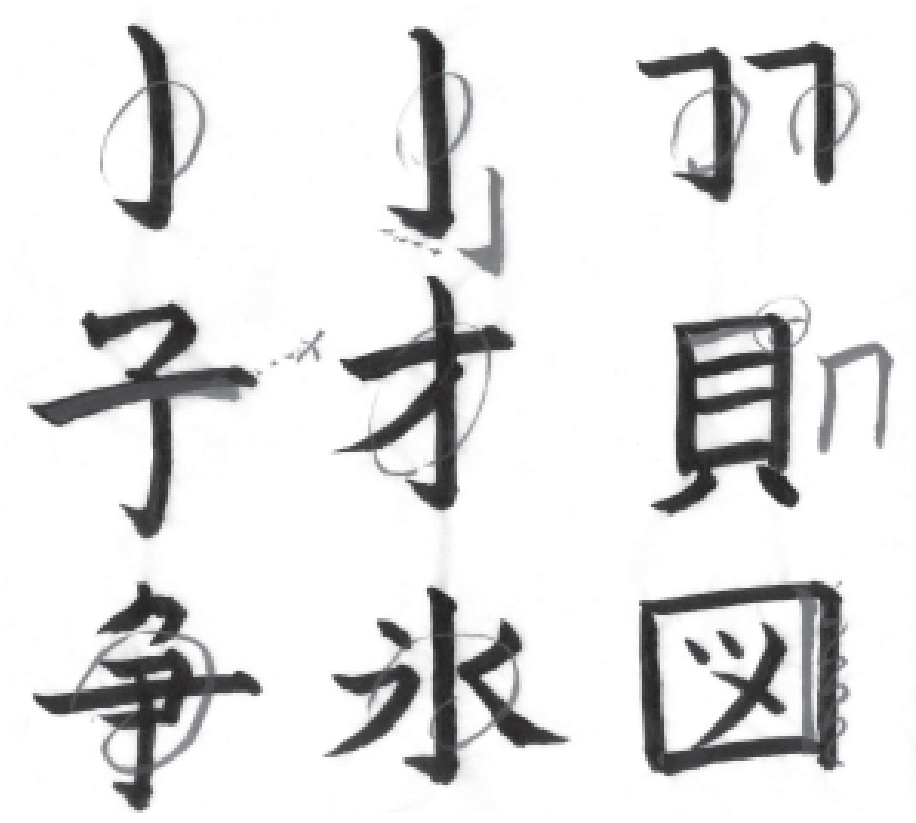

Figura 7 - Exemplo de fragmento de manuscrito com traços básicos - linha de cima - (acervo do autor) 
A caligrafia japonesa possui, de fato, sob uma perspectiva mais ampla, dois trajetos possíveis no que diz respeito à escolha do conteúdo: trabalhase ou com caracteres inteiros, ou com elementos recorrentes nesses caracteres, os traços básicos. Nos manuscritos analisados, identificou-se a presença de alguns desses traços, cuja execução se deu juntamente com a de caracteres inteiros, em seqüências dos modelos de caligrafia. Cabe ressaltar, no entanto, que, embora nessa produção não tenha havido manuscritos exclusivamente com traços básicos, isso pode ser realizado. No que se segue, há uma amostra de como foram trabalhados com o aprendiz os traços básicos nas aulas da Esperança Fujinkai (Figura 7) e um exemplo de tehon feito para a prática exclusiva desses traços (Figura 8).

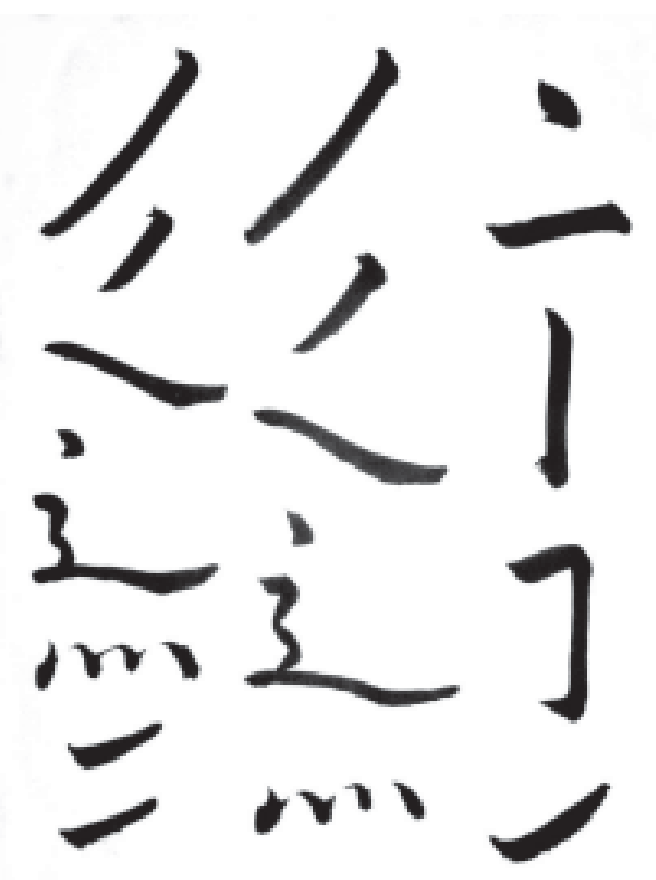

Figura 8 - Exemplo de um modelo (tehon) voltado para a prática exclusiva de traços básicos, de Shoka Kodera (cortesia da professora) de shodô

Já no que se refere à organização do conteúdo pela professora, observou-se, nos manuscritos, que, no período em questão, foram constituídos dois estágios da prática do shodô: um introdutório, outro intermediário.

No primeiro estágio, foram desenvolvidas grafias simples e básicas, isto é, o hiragana e o katakana (nessa ordem): simples, pois seus caracteres são compostos por poucos traços e partes, diferentemente do kanji; básicas, porque os traços que contêm essas grafias compõem ainda os ideogramas e, então, sua prática, além de um fim por si só, constitui também um meio para a assimilação da grafia ideográfica. Nesse estágio, além disso, foram desenvolvidos não estilos propriamente, mas o que se chamou de "aproximações" de estilos. Trata-se de formas das grafias silábicas, hiragana e katakana, que, 
apesar de situadas próximas ao sôsho e ao kaisho, respectivamente, não se configuram estritamente como tal - sua prática parece ter sido, na realidade, uma preparação para o exercício desses estilos.

No segundo estágio da prática do shodô, por sua vez, foi transmitida a grafia mais complexa, ou seja, a ideográfica, e isso foi feito a partir de dois estilos, o kaisho e o gyôsho, nessa ordem - tendo sido efetuada, portanto, uma condução do aprendiz do rígido ao (levemente) flexível. Verificou-se, nesse estágio intermediário, ainda, que a apresentação de novos caracteres (ideogramas) compôs um percurso que foi do simples ao complexo e do complexo ao simples, progressivamente. A seqüência apresentada na Figura 9 exemplifica isso.

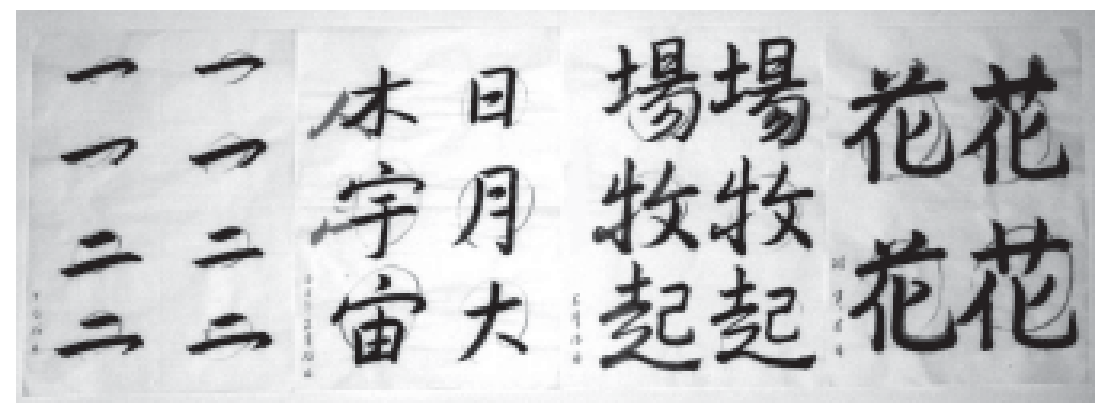

Figura 9 - Seqüência de manuscritos em gyôsho. Da esquerda para a direita, manuscritos produzidos em setembro de 2004, fevereiro de 2005, maio de 2005 e julho de 2005 (acervo do autor)

No primeiro manuscrito, registro da introdução do aprendiz no gyôsho, são observados dois caracteres simples: ichi (número um, em japonês) e ni (número dois) - respectivamente, os quatro caracteres de cima e os quatro de baixo. Mais à frente, o aluno foi orientado a executar caracteres um pouco mais complexos, mas, ainda assim, simples, como ki (árvore) e hi (sol) respectivamente, os ideogramas localizados nos cantos superiores esquerdo e direito. Adiante, a professora apresentou ao aluno outro tehon, no qual havia ideogramas constituídos já por duas partes, como jô (idéia de lugar) e okiru (acordar), com complexidade superior à dos anteriores - os dois ideogramas de cima e os dois de baixo, respectivamente. Por fim, voltou-se ao simples: no manuscrito seguinte, o aprendiz foi instruído à execução do caractere hana (flor), menos complexo do que os ideogramas precedentes. Note-se entretanto que, nesse último manuscrito, há tanto o gyôsho (à esquerda) quanto o kaisho (à direita); assim, nesse momento, a professora visou, possivelmente, a compreensão, pelo aluno, das diferenças entre os dois estilos, o que está um passo na frente da execução de ambos.

Outro aspecto observado nos manuscritos e que se relaciona ao trabalho com o conteúdo foi o ritmo do desenvolvimento de grafias, estilos e caracteres. Nos primeiros dois meses, manteve-se um ritmo moderado, sendo apresentados ao aluno apenas cerca de nove caracteres do hiragana (na 
forma de uma aproximação do sôsho), por aula, até sua conclusão. Em seguida, deu-se início ao desenvolvimento do katakana (como aproximação do kaisho). Dessa vez, entretanto, foram apresentados 27 caracteres ao aluno em uma única aula - tendo sido essa grafia e estilo (aproximação) finalizados em um mês somente. A princípio, pensou-se que pudesse haver um aumento contínuo na velocidade de transmissão do shodô. Contudo, o que se encontrou aí foi uma exceção. A opção pela apresentação de um maior ou menor número de caracteres novos e pela inserção do aprendiz em outros estilos parece ter levado em consideração, sobretudo, a complexidade que têm esses caracteres e estilos e o repertório do aluno. Embora haja, entre o hiragana e o katakana praticados, uma diferença significativa na condução do traço (o primeiro exigiu flexibilidade; o segundo, rigidez), há entre eles também homogenia no que diz respeito à complexidade - caracteres de um e de outro são compostos por poucos traços e partes. Acredita-se que justamente essa homogeneidade tenha sido responsável pelo trabalho rápido que se fez com o katakana. Nos manuscritos, verificou-se que, em geral, a inserção de novos elementos na prática do shodô foi compassada e, ainda, que a introdução do aluno em novos estilos se deu somente quando este apresentou um domínio razoável daquilo que vinha sendo praticado até então.

Observou-se que o desenvolvimento do shodô não visou, pois, uma grande variedade de caracteres e um exercício rápido dos estilos; voltou-se, antes, a um número reduzido daqueles e a uma prática detida destes. Isso significa também que o trabalho com o conteúdo do shodô se deu, em grande parte, pela repetição de um mesmo conjunto de elementos. Entretanto, essa repetição não se limitou a um ato mecânico; teve por objetivo tanto o domínio da técnica quanto a impressão de vida (ou expressão individual do autor) aos caracteres.

Nos manuscritos, pôde-se verificar, ainda, que a repetição dos elementos, no período em questão, se deu em dois momentos: logo após sua apresentação pela professora e depois da análise da produção do aprendiz pela sensei. No último caso, não necessariamente foram reproduzidos todos os caracteres praticados; muitas vezes, foram feitos novamente somente aqueles nos quais foram detectadas dificuldades maiores. A seqüência constante da Figura 10 exemplifica isso.

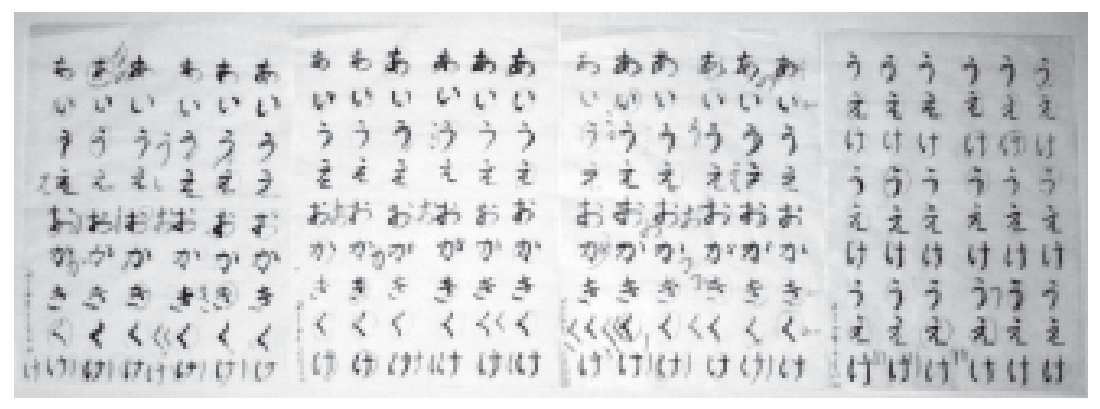

Figura 10 - Seqüência de manuscritos que retrata o exercício da repetição, na prática do shodô (acervo do autor) 
Os caracteres a, $i, u, e, o, k a, k i, k u$ e $k e$ (de cima para baixo) foram reproduzidos no primeiro, segundo e terceiro manuscritos da seqüência. Já no quarto essa reprodução restringiu-se a $u$, e e ke. Aparentemente, as deficiências do aluno concentravam-se nesses caracteres e, então, no último manuscrito, a reprodução limitou-se a u, e e ke.

Por último, observou-se, nos manuscritos, flexibilidade no que diz respeito ao trabalho com o conteúdo, não rigidez. Detectou-se sua presença, especificamente, a partir da variação notada com relação ao número de caracteres executados por manuscrito e, conseqüentemente, no que se refere ao tamanho desses caracteres. A seqüência apresentada na Figura 11 mostra isso.

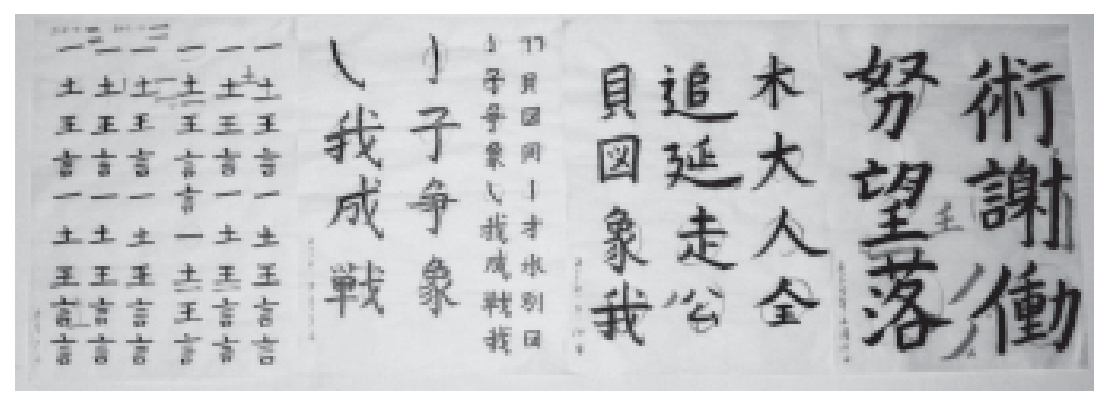

Figura 11 - Manuscritos produzidos, da esquerda para a direita, em maio de 2004, em setembro de 2004, em setembro de 2004 e em fevereiro de 2005

No primeiro manuscrito, à esquerda, seguiu-se o padrão do curso de shodô da Esperança Fujinkai, isto é, foram produzidos nove caracteres por coluna e seis colunas por manuscrito. Já na peça seguinte o espaço branco foi ocupado por caracteres e traços tanto no formato anterior quanto em um formato maior: um terço do papel foi utilizado para a prática de traços e caracteres pequenos; dois terços, para traços e caracteres grandes. Logo adiante, nos dois outros manuscritos, observa-se que se manteve apenas a prática do formato maior de caracteres. Essa transição de formatos sinaliza a flexibilidade apontada, porque em vez de ser mantido, com rigor, o formato inicial, procedeu-se a adaptações, dirigidas, possivelmente, às particularidades do aluno.

\section{Resultados - aspectos observados na correção}

Observou-se, nos manuscritos, que o olhar da professora de shodô se ateve a aspectos de três níveis da produção do aprendiz: traço; caractere; caractere e sua relação com o conjunto.

Primeiramente, no que diz respeito ao nível do traço, verificou-se que as correções e observações da sensei dirigiram-se à execução do início e término dos traços (respectivamente, hajime e owari), às trajetórias intermediárias dos traços e, ainda, às conexões entre as diferentes partes que podem compor um mesmo traço. 
Sobretudo quando se trata do kaisho, os traços compostos por uma única parte são realizados em três turnos: coloca-se o pincel em contato com o papel, preparando-se para a execução da trajetória intermediária do traço; executa-se a trajetória intermediária do traço; finaliza-se o traço, afastando-se o pincel da superfície do papel. O primeiro e terceiro turnos exigem do praticante conhecimento dos efeitos que dão as diferentes formas de se manipular os pêlos do pincel no espaço branco. Já a execução do trajeto intermediário do traço requer do aluno a percepção da direção, comprimento, curvatura, força e espessura de cada traço, além de um domínio suficiente do pincel para a composição de um percurso fiel a essa percepção. Na produção do aprendiz, a professora de shodô fez correções e observações referentes a esses aspectos, como nos exemplos a seguir.

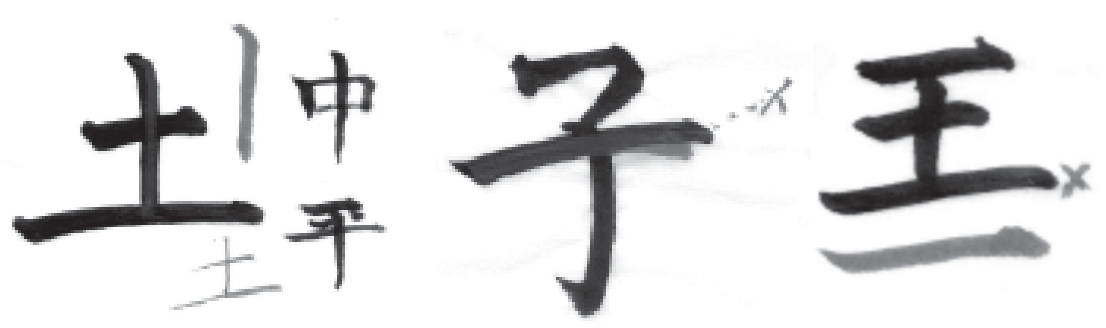

Figuras 12, 13 e 14 - Exemplos de correções no nível do traço

No primeiro exemplo, à esquerda, o traço vertical do ideograma tsuchi (terra) exige em seu início não a condução do pincel da esquerda para a direita, como realizado, mas a inclinação do pincel para a diagonal inferior direita, e isso foi observado pela professora. No exemplo seguinte, há o apontamento da direção correta do traço no kanji ko (criança): levemente descendente, e não ascendente, como executado. No último exemplo, o modo adequado de finalizar o quarto traço do ideograma ô (rei) foi enfatizada pela sensei. O pincel, aí, deve fazer um leve movimento retroativo, diferente da finalização feita, sem retroação.

No caso de traços compostos por mais de uma parte, as correções feitas pela professora dirigiram-se aos mesmos aspectos citados acima. Somou-se a eles, entretanto, a ênfase dada à maneira pela qual as diferentes partes de um mesmo traço são conectadas. A seguir, há dois exemplos disso. No primeiro, chamou-se a atenção para a conexão das partes que constituem o segundo traço do ideograma naka (centro) - é necessário que haja reta e pontas bem definidas no canto desse ideograma. No segundo exemplo, as conexões entre a segunda e a terceira e a terceira e a quarta partes do caractere so (hiragana) foram alvo das correções. Após os traços de ida, é preciso voltar (modoru, em japonês, como está escrito em cinza) para dar continuidade à composição desse caractere. 

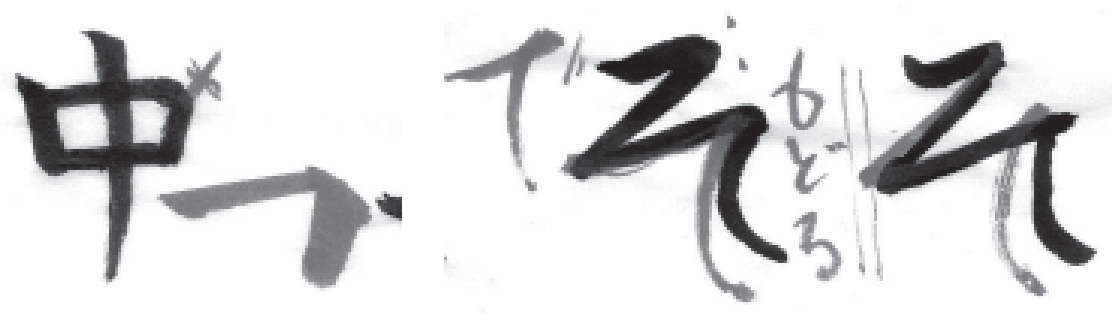

Figuras 15 e 16 - Exemplos de correções dirigidas à conexão entre as diferentes partes de um mesmo traço

No que se refere ao nível do caractere, as observações e correções da professora voltaram-se, inicialmente, à proporção das partes do caractere com relação ao seu todo e ao posicionamento de traços ou partes do caractere com relação ao seu conjunto. Abaixo, têm-se exemplos de correções voltadas a esses dois aspectos.
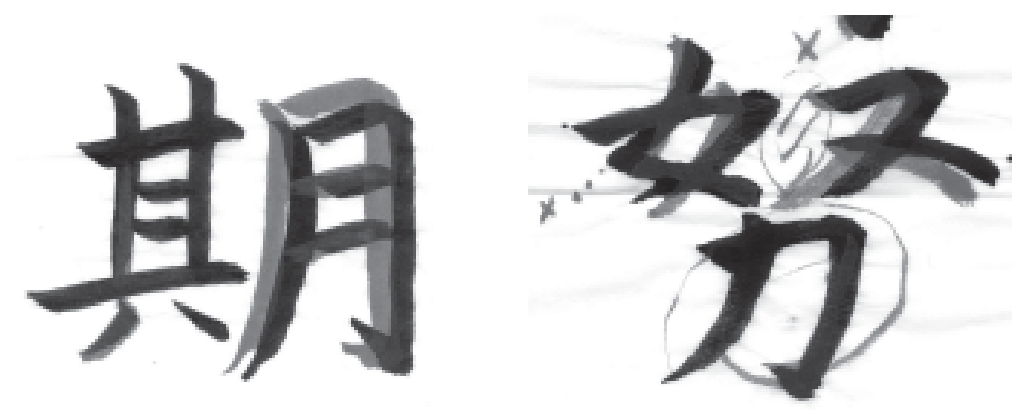

Figuras 17 e 18 - Exemplos de correções feitas no nível do caractere

No primeiro exemplo (à esquerda), o tamanho e o posicionamento da parte direita do ideograma foram remendados, a fim de que fosse constituído, aí, de fato, um único kanji- da maneira como tinha sido feito, não havia uma relação bem estabelecida entre as partes, em decorrência da distância e da diferença de tamanho existente entre elas. No segundo exemplo, a parte superior direita do kanji situava-se distante das demais partes, e isso foi observado pela professora. Nesse ideograma, para que se componha um todo, não deve haver espaço entre as duas partes superiores do kanji.

Além disso, no nível do caractere foram observadas ainda a ordem dos traços dos caracteres e a conexão existente entre as diferentes partes de um mesmo caractere, tratando-se do gyôsho (estilo no qual essa conexão é feita); os exemplos a seguir contêm correções e observações voltadas a esses aspectos. No primeiro, à esquerda, o resultado da execução do ideograma hito (sozinho) denunciou falhas na composição do kanji quanto à ordem dos traços. A professora, então, enumerou a ordem correta dos traços da parte esquerda do ideograma. No outro exemplo é sinalizada a conexão existente entre o terceiro e quarto traços do ideograma ki (árvore), 
que não havia sido efetuada pelo praticante. No gyôsho, estilo flexível, esse tipo de conexão é comum e consiste em característica que o distingue do kaisho, rígido.
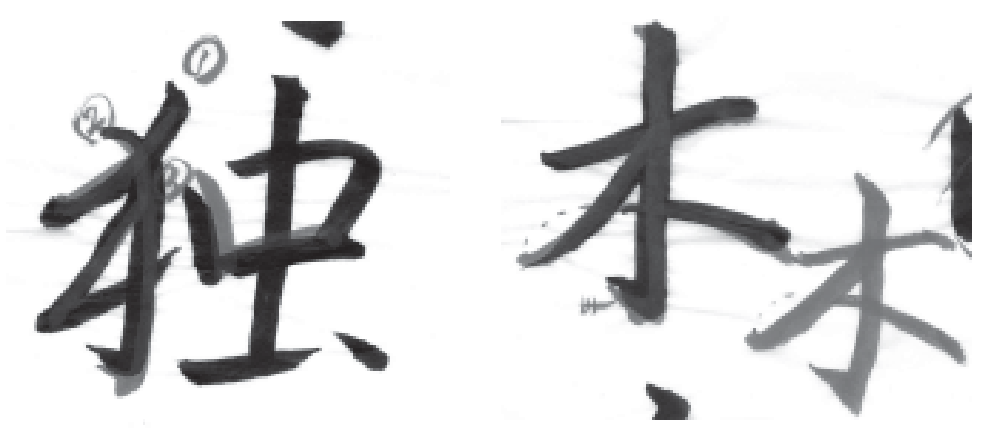

Figuras 19 e 20 - Exemplos de correções dirigidas à ordem dos traços (esquerda) e à conexão entre os diferentes traços de um mesmo ideograma no estilo gyôsho (direita)

Por último, quanto ao nível do caractere e sua relação com o conjunto, verificou-se que as observações e correções da professora dirigiram-se ao espaço que deve existir entre os caracteres realizados e ao espaço que deve haver entre os caracteres e as bordas do papel. Os exemplos abaixo são uma amostra disso.
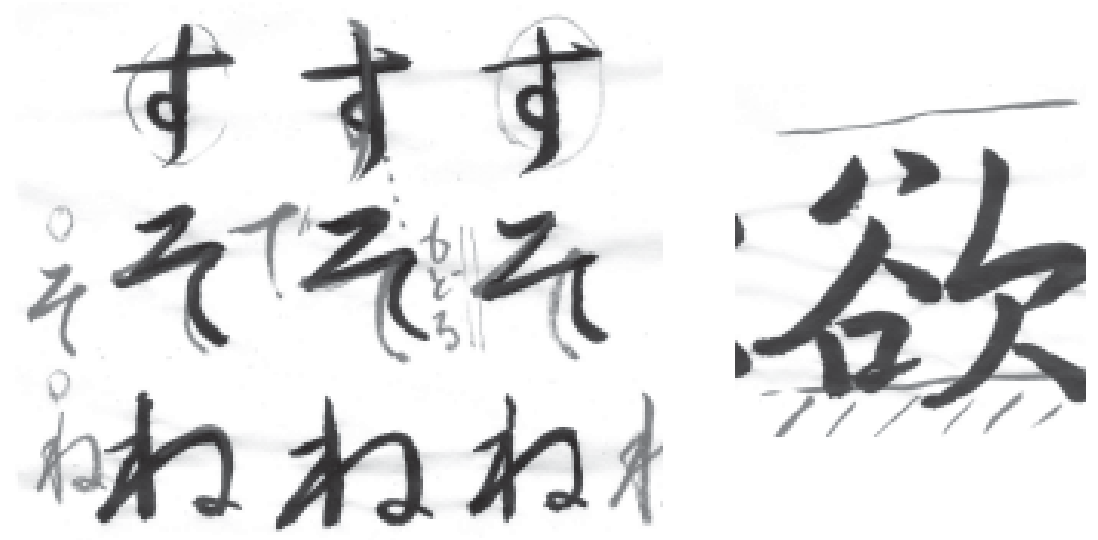

Figuras 21 e 22 - Exemplos de observações no nível do conjunto de caracteres

À esquerda, em cinza, é sinalizado com pequenos círculos o espaço que deve existir entre os caracteres de uma mesma coluna. Essa observação dirigiu-se, especificamente, à segunda coluna, na qual, entre o primeiro e segundo elementos do hiragana (su e so), houve uma aproximação excessiva - apesar de minimamente excessiva. Já no outro exemplo trata-se de um ideograma realizado no canto inferior direito do papel, cuja execução 
não respeitou o espaço que precisa existir entre os ideogramas e as bordas do washi. Apesar de, nos traços do shodô, linhas simétricas ou paralelas não serem, geralmente, visadas, quando se trata do conjunto de um manuscrito, um uso do espaço com iguais proporções na peça é valorizado.

\section{Discussão}

A partir da análise dos manuscritos, pôde-se apreender diferentes aspectos relacionados com o ensino do shodô.

Por meio do primeiro escopo, foi possível verificar qual conteúdo foi trabalhado nos estágios introdutório e intermediário de um aluno dessa arte, também como foi organizado o desenvolvimento desse conteúdo, o ritmo em que se deu esse desenvolvimento e o formato estabelecido para o trabalho em questão. Esses aspectos tocam, certamente, em grande parte do que se pode explorar, caso se tenha em foco o ensino, qualquer que seja a natureza da disciplina.

Cabe assinalar, com relação ao conteúdo, entretanto, que, por ter sido examinada a produção de um aluno sem ascendência japonesa, o trabalho com o katakana foi identificado. A prática dessa grafia no shodôé, em geral, deixada de lado, e isso deve ser observado. Por se tratar de um aprendiz sem ascendência japonesa - e, portanto, sem nome japonês -, o katakana seria necessário, sobretudo, para assinar os seus trabalhos, e, por isso, foi desenvolvido. Entre os japoneses, porém, apesar de sua aplicação ter também fins práticos, ela é, como aponta Nakata (1983), limitada.

Já a partir do segundo escopo, pôde-se identificar a quais aspectos da produção de um aprendiz se dirige a atenção de um professor de shodô. Por um lado, trata-se de pontos que, sob a perspectiva da educação, se situam próximos aos conceitos de avaliação e acompanhamento (contínuo, no caso) dos alunos. Por outro lado, consiste também em uma trajetória que pode ser empregada para a análise de qualquer trabalho de caligrafia japonesa (ou chinesa): parte-se do traço; segue-se para o nível do caractere; observa-se, ao final, a relação de cada um dos caracteres com o conjunto constituído.

Deve-se apontar, contudo, ainda, a existência de um quarto nível na análise da produção, que, no exame dos manuscritos, não pôde ser observado: o nível dos materiais. Existem diferentes tipos de papel, tinta e pincel, e isso é analisado também no trabalho dos alunos pelo professor - assim como a utilização dessas ferramentas. O papel é adequado aos caracteres e estilos praticados (caracteres maiores exigem papéis mais grossos; estilos suaves, muitas vezes, papéis finos, etc.)? A tinta está bem misturada? E a quantidade de água é suficiente? Nesse outro nível de análise, por fim, aspectos como esses são visados.

\section{Considerações finais}

Cabem aqui, por último, breves considerações (ou questionamentos) sobre o ensino do shodô, sob uma perspectiva mais ampla. 
No Brasil, talvez, a teoria mais difundida no ensino de arte seja a abordagem triangular. Sob sua perspectiva, esse ensino integra "o fazer artístico, a leitura desse fazer individual dos fazeres dos outros e sua contextualização no tempo" (Barbosa, 1990, p. 8). Neste trabalho investigaram-se, sobretudo, resultados do fazer artístico; "sobretudo", e não "exclusivamente", pois, como pode ser a leitura do ensino do shodô pela lente da abordagem triangular, se os caracteres e estilos praticados são os mesmos que aqueles de séculos ou milênios atrás e se a análise mistura-se, muitas vezes, com o fazer arte? Trata-se de uma questão interessante para o ensino do shodô e que, neste trabalho, deixar-se-á aberta.

Por fim, outras indagações que surgiram ao longo deste trabalho e que, espera-se, sejam melhor compreendidas, ainda que minimamente, ao longo da pesquisa que este estudo integra, referem-se à existência de uma tradição na transmissão do shodô e à possível influência da compreensão (ou não-compreensão) do idioma japonês no aprendizado dessa arte. Por consistir a arte da caligrafia japonesa numa arte tradicional, a primeira questão tomou forma. E, por constituírem o conteúdo do shodô as escritas chinesa e japonesa, a segunda questão é relevante, sobretudo caso se pense na difusão dessa arte para brasileiros sem conhecimento do japonês, com ou sem ascendência japonesa.

\section{Referências bibliográficas}

BARBOSA, Ana Mae. Introdução. In: BARBOSA, Ana Mae; SALES, Heloisa Margarido (Org.). Simpósio internacional sobre o ensino da arte e sua história. São Paulo: MAC/USP, 1990. p. 6-9.

FERRAZ, Maria Heloísa Corrêa de Toledo; FUSARI, Maria Felisminda de Rezende. Metodologia do ensino de arte. São Paulo: Cortez, 1991. 135 p.

GINZBURG, Carlo. Sinais: raízes de um paradigma indiciário. In: Mitos, emblemas, sinais: morfologia e sua história. São Paulo: Companhia das Letras, 1990. p. 143-179.

MIKAMI, Takahiko; TANAHASHI, Kazuaki. You and Japanese brushwriting. Tokyo: Hozansha, Publishing Company, 1961. 109 p.

NAKATA, Yujiro. The art of Japanese calligraphy (The Heibonsha Survey of Japanese Art - Volume 27). Tradução de Alan Woodhull e Armins Nikovskis. Tokyo: Heibonsha, 1983. 172 p.

SAITO, Cecília Noriko Ito. O shodô, o corpo e os novos processos de significação. São Paulo: Annablume, 2004. 78 p. 
SATO, Christine Flint. Japanese calligraphy: the art of line and space. Osaka: Mitsuru Sakui, 1999. p. 103.

SUZUKI, Tae. A escrita japonesa. Estudos Japoneses, São Paulo, v. 5, p. 53-61, 1985.

WAKAMATSU, Joku. Shodo: caligrafia. In: OTA, J. et al. Dô - A essência da cultura japonesa. São Paulo: Chado Urasenke do Brasil, 2004. p. 68-83.

Rodrigo Moura Lima de Aragão, bacharel em Propaganda pela Universidade Presbiteriana Mackenzie, é especialista em Administração pela Fundação Getúlio Vargas (FGV), pesquisador do Centro de Estudos Japoneses da Universidade de São Paulo e bolsista do Programa de Iniciação Científica da província de Toyama (Japão).

aragao_rodrigo@yahoo.com.br

Recebido em 19 de outubro de 2006.

Aprovado em 22 de novembro de 2006. 